\title{
Association of moderate aerobic exercise and rho-associated kinase 2 concentration in subjects with dyslipidemia
}

\author{
Huadong Bai ${ }^{1}$, Jingchun Sun ${ }^{2}$, Guiying $\mathrm{Du}^{3}$, Fengjun Jiao ${ }^{4}$
}

\author{
${ }^{1}$ Department of Cardiology, Zhengzhou Central Hospital, Zhengzhou, Henan Province, \\ China \\ 2Department of Cardiology, Shanxian Central Hospital, Heze, Shandong Province, \\ China \\ ${ }^{3}$ Department of Cardiology, People's Hospital of Lingcheng District, Dezhou, Shandong \\ Province, China \\ ${ }^{4}$ Department of Cardiology, The First People's Hospital of Xianyang, Xianyang, Shanxi, \\ China
}

Submitted: 2 August 2016

Accepted: 17 October 2016

Arch Med Sci 2017; 13, 4: 807-812

DOI: https://doi.org/10.5114/aoms.2017.68142

Copyright $\odot 2017$ Termedia \& Banach

\section{Abstract}

Introduction: Dyslipidemia is associated with increased rho-associated kinase 2 (ROCK2) concentration. Whether moderate aerobic exercise could attenuate leukocyte ROCK2 concentration is unknown.

Material and methods: One hundred subjects with dyslipidemia and without statin treatment were enrolled and assigned to exercise and control groups. In the exercise group, at least 30 min of moderate aerobic exercise per day 5 times weekly was recommended. In the control group, participants were recommended to undertake exercise of the same intensity as the exercise group but not mandatorily. At baseline and 3 months later, between-group differences were compared.

Results: At baseline, dyslipidemia in both groups was characterized by increased serum levels of total cholesterol and low density lipoprotein cholesterol (LDL-C). Serum high-sensitivity C-reactive protein (hs-CRP) level was comparably increased too, and the average daily exercise time was extremely low: $5.8 \pm 2.7 \mathrm{~min}$ and $6.2 \pm 3.1 \mathrm{~min}$ respectively. Leukocyte ROCK2 concentration in the two groups was $38.4 \pm 7.5 \mathrm{mg} / \mathrm{ml}$ and $40.2 \pm 8.2 \mathrm{mg} / \mathrm{ml}$ respectively. Three months later, compared with the control group, average daily exercise time was significantly longer in the exercise group ( $37.4 \pm 4.3$ $\min$ vs. $16.5 \pm 7.5 \mathrm{~min}, p<0.05$ ). Leukocyte ROCK2 concentration was also significantly reduced $(27.6 \pm 4.3 \mathrm{mg} / \mathrm{ml}$ vs. $34.6 \pm 5.2 \mathrm{mg} / \mathrm{ml}, p<0.05)$. Serum nitric oxide (NO) concentration in the exercise group was significantly higher than the control group $(p<0.05)$. Multivariate linear regression analysis revealed that $\mathrm{NO}$ and exercise time were significantly associated with leukocyte ROCK2 concentration after adjusting for traditional risk factors. Conclusions: Moderate aerobic exercise could effectively attenuate leukocyte ROCK2 concentration in subjects with dyslipidemia.

Key words: dyslipidemia, aerobic exercise, rho-associated kinase.

\section{Introduction}

Atherosclerosis is recognized as a chronic inflammatory disease which is mainly characterized by endothelial dysfunction $[1,2]$. Endothe-

\author{
Corresponding author: \\ Fengjun Jiao \\ Department of Cardiology \\ The First People's \\ Hospital of Xianyang \\ Fu No. 10, Biyuan Road \\ Xianyang, Shanxi Province \\ China, 712000 \\ Phone: +86 2933288218 \\ Fax: +86 2933288218 \\ E-mail: jiaofengjun123@sina. \\ com
}


lial dysfunction, as defined by decreased generation of nitric oxide (NO), is known to contribute to increased endothelium permeability thereby enhancing leukocyte infiltration and accumulation within the vascular wall [3]. Previously, a substantial amount of studies have consistently revealed that in morbid conditions such as dyslipidemia, hypertension and diabetes mellitus, increased leukocyte rho-associated kinase (ROCK) concentration leads to the initiation and progression of atherosclerosis [4-6], and the underlying mechanisms operating in these processes include ROCK's actions on increasing reactive oxygen species (ROS) generation and destabilizing endothelial nitric oxide synthase (eNOS) mRNA [7-9]. Therefore, it is conceivable that reduced ROCK expression may confer cardiovascular benefits. Indeed, some experimental studies show that a ROCK inhibitor, fasudil or Y-27632, is beneficial for improving endothelial dysfunction, ameliorating oxidative stress and inflammatory reactions, which together contribute to improvement of cardiac remodeling and cardiac function [10-12] However, due to the lack of solid evidence, currently, no ROCK inhibitor has been approved for the treatment of atherosclerosis and atherosclerotic cardiovascular diseases (ASCVD).

At present, increasing moderate aerobic exercise is strongly recommended for the primary and secondary prevention of ASCVD [13-15]. The mechanisms associated with clinical benefits derived from moderate aerobic exercise are partially due to its effects on improving cholesterol and glucose metabolism, which thereby improve endothelial function and inflammation [14-16]. However, whether moderate aerobic exercise can attenuate leukocyte ROCK concentration has not been well studied yet.

With respect to the epidemic of dyslipidemia in the last decade, it is warranted to evaluate whether the most cost-effective element of lifestyle, that is moderate aerobic exercise, can improve dyslipidemia. Moreover, whether these benefits are related to ROCK reduction also deserved assessment. We therefore conducted a study to clarify whether moderate aerobic exercise is beneficial for reducing leukocyte ROCK2 (a significant isoform of the ROCK family) concentration in subjects with dyslipidemia.

\section{Material and methods}

\section{Study participants}

One hundred participants with newly diagnosed dyslipidemia who had no history of ASCVD, hypertension, diabetes mellitus, or other liver, renal or rheumatic diseases were enrolled after oral informed consent was obtained. The pres- ent study was approved by the ethic committee of clinical research of the participating hospital. None of the participants had been treated with lipid-lowering treatment before. Initially, 100 participants were randomly assigned into the exercise group $(n=50)$, in whom at least $30 \mathrm{~min}$ of moderate aerobic exercise (in terms of fast walking or jogging) per day 5 times every week was strongly recommended and was monitored closely by the study investigators. The other 50 participants in the control group were also recommended to undertake exercise of the same intensity as subjects in the exercise group, but it was not mandatorily required and monitored closely. At baseline and 3 months later, demographic and biochemical variables were recorded by two working investigators and were rechecked by the third investigator. Fasting venous blood was drawn, and all the biochemical measurements were performed in the laboratory center of the participating hospital.

\section{Measurement of serum NO concentration}

Total NO was evaluated by the nitrite reductase method using the Total Nitric Oxide Kit (Beyotime Company, China, S0024). All the procedures were performed in accordance with the manufacturer's protocol. NO production at baseline and 3 months later was evaluated. Briefly, $10 \mathrm{ml}$ of fasting venous blood was drawn and was quantified by the bicinchoninic acid (BCA) assay. Sodium nitrite $\left(\mathrm{NaNO}_{2}\right)$ supplied within the Total Nitric Oxide Kit was used to determine the standard curve. Optical density of each sample was detected by an enzyme-labeling measuring instrument at a wavelength of $540 \mathrm{~nm}$, and the concentration was determined from the standard curve. All the measurements were repeated 3 times to determine the arithmetic mean.

\section{Leukocyte ROCK2 concentration assessment}

Enzyme-linking immune-sorbent assay (ELISA kit, Abcam company, ab160505) was used to evaluate leukocyte ROCK2 concentration. Fasting venous samples were drawn and stored at $-80^{\circ} \mathrm{C}$ until use. All the procedures were in accordance with the manufacturer's instructions, and all the measurements were repeated 3 times to determine the arithmetic mean.

\section{Statistical analysis}

Continuous data were presented as mean \pm standard deviation (SD) or median (inter-quartile range) as appropriate, and were compared by the Student's $t$-test when data were normally distributed; otherwise they were compared by the Wilcoxon rank-sum test. Categorical data were pre- 
sented as percentages and compared by $\chi^{2}$ test. Multivariate linear regression analysis was conducted to evaluate the relationship between exercise and other variables with the leukocyte ROCK2 concentration. All reported $p$-values were 2 -sided, and a $p$-value of $<0.05$ was considered statistically significant. All statistical analyses were conducted with the SPSS statistical package for Windows version 19.0 (SPSS Inc., Chicago, Illinois).

\section{Results}

\section{Baseline characteristics of studied subjects}

There was no significant difference in baseline characteristics between these two groups, as shown in Table I. The ages of the two groups were $49.6 \pm 6.3$ and $48.3 \pm 8.1$ years, and subjects were predominantly male $(72.0 \%$ vs. $70.0 \%)$. At baseline, both groups were characterized by increased serum levels of total cholesterol, low-density lipoprotein cholesterol (LDL-C), apoB100 and $\mathrm{Lp}(\mathrm{a})$ accompanied with decreased serum levels of high-density lipoprotein cholesterol (HDL-C) and apoA1. Of note, no significant differences in lipid profiles were observed. Serum high sensitivity C-reactive protein (hs-CRP) level was comparably increased in both groups, and the average daily exercise time of both groups was extremely low, at $5.8 \pm 2.7 \mathrm{~min}$ and $6.2 \pm 3.1 \mathrm{~min}$, respectively. Leukocyte ROCK2 concentration in the two groups was $38.4 \pm 7.5 \mathrm{mg} / \mathrm{ml}$ and $40.2 \pm 8.2 \mathrm{mg} / \mathrm{ml}$, respectively. Overall, no differences in baseline characteristics were observed between the two groups.

\section{Comparisons of characteristics after 3 months}

Three months later, 42 participants in the exercise group had completed the exercise program in terms of at least 30 min of daily moderate aerobic exercise 5 times per week, and the other 8 participants who could not finish this program were excluded from the final analyses. Compared with the control group, the average daily exercise time was significantly longer in the exercise group (37.4 $\pm 4.3 \mathrm{~min}$ vs. $16.5 \pm 7.5 \mathrm{~min}, p<0.05$ ), although exercise time in the control group was also increased compared to baseline (16.5 \pm 7.5 $\min$ vs. $6.2 \pm 3.1 \mathrm{~min}, p<0.05)$. Leukocyte ROCK2 concentration was significantly lower in the exercise group compared with the control group (27.6 $\pm 4.3 \mathrm{mg} / \mathrm{ml}$ vs. $34.6 \pm 5.2 \mathrm{mg} / \mathrm{ml}, p<0.05)$. In addition, serum levels of LDL-C, HDL-C, Lp(a) and hsCRP were also significantly lower in the exercise group ( $p<0.05)$. Notably, as shown in Table II, some variables such as smoking, serum $\operatorname{Lp}(\mathrm{a})$ and hs-CRP levels, and leukocyte ROCK2 concentration in the control group were slightly improved when compared with baseline.

\section{Changes of serum NO concentration}

At baseline, serum NO concentrations in the exercise $(17.8 \pm 2.6 \mu \mathrm{mol} / \mathrm{l})$ and control groups $(18.3 \pm 3.1 \mu \mathrm{mol} / \mathrm{l})$ were comparable. Nonetheless, 3 months later, serum NO concentration in the exercise group improved significantly more than that in the control group: $30.6 \pm 4.5 \mu \mathrm{mol} / / \mathrm{vs} .22 .6$ $\pm 3.9 \mu \mathrm{mol} / \mathrm{l}(p<0.05)$.

\section{Relationship between exercise and other variables with leukocyte ROCK2 concentration}

In order to investigate the association of the degree of exercise and other variables and leuko-

Table I. Baseline characteristics comparisons

\begin{tabular}{|c|c|c|}
\hline Variables & $\begin{array}{l}\text { Exercise } \\
(n=50)\end{array}$ & $\begin{array}{l}\text { Control } \\
(n=50)\end{array}$ \\
\hline Age [years] & $49.6 \pm 6.3$ & $48.3 \pm 8.1$ \\
\hline Male, $n(\%)$ & $36(72.0)$ & $35(70.0)$ \\
\hline $\mathrm{BMI}\left[\mathrm{kg} / \mathrm{m}^{2}\right]$ & $23.2 \pm 3.5$ & $23.8 \pm 3.0$ \\
\hline Smoking, $n(\%)$ & $14(28.0)$ & $15(30.0)$ \\
\hline $\mathrm{SBP}[\mathrm{mm} \mathrm{Hg}]$ & $118.2 \pm 13.6$ & $120.6 \pm 11.5$ \\
\hline $\mathrm{DBP}[\mathrm{mm} \mathrm{Hg}]$ & $73.6 \pm 9.2$ & $71.8 \pm 9.7$ \\
\hline $\mathrm{HR}$ [bpm] & $75.4 \pm 6.6$ & $77.1 \pm 5.5$ \\
\hline $\mathrm{TG}[\mathrm{mmol} / \mathrm{l}]$ & $1.4 \pm 0.3$ & $1.5 \pm 0.2$ \\
\hline $\mathrm{TC}[\mathrm{mmol} / \mathrm{ll}]$ & $5.8 \pm 0.3$ & $5.8 \pm 0.4$ \\
\hline LDL-C [mmol/I] & $3.9 \pm 0.4$ & $3.8 \pm 0.5$ \\
\hline $\mathrm{HDL}-\mathrm{C}[\mathrm{mmol} / \mathrm{l}]$ & $0.9 \pm 0.2$ & $0.9 \pm 0.1$ \\
\hline apoA1 [mmol/l] & $1.0 \pm 0.3$ & $1.0 \pm 0.2$ \\
\hline apoB100 [mmol/l] & $1.9 \pm 0.2$ & $2.0 \pm 0.3$ \\
\hline $\mathrm{Lp}(\mathrm{a})[\mathrm{mg} / \mathrm{l}]$ & $132.4 \pm 15.6$ & $135.7 \pm 17.3$ \\
\hline $\mathrm{FBG}[\mathrm{mmol} / \mathrm{l}]$ & $5.4 \pm 0.5$ & $5.6 \pm 0.3$ \\
\hline $\mathrm{Cr}[\mu \mathrm{mol} / \mathrm{l}]$ & $93.3 \pm 11.5$ & $91.7 \pm 9.4$ \\
\hline BUN [mmol/l] & $5.2 \pm 1.0$ & $5.4 \pm 1.1$ \\
\hline $\mathrm{Hs}-\mathrm{CRP}[\mathrm{mg} / \mathrm{l}]$ & $4.5 \pm 1.3$ & $4.6 \pm 1.0$ \\
\hline $\begin{array}{l}\text { ROCK2 concentration } \\
{[\mathrm{mg} / \mathrm{ml}]}\end{array}$ & $38.4 \pm 7.5$ & $40.2 \pm 8.2$ \\
\hline $\begin{array}{l}\text { NO concentration } \\
{[\mu \mathrm{mol} / \mathrm{l}]}\end{array}$ & $8.3 \pm 1.1$ & $8.9 \pm 1.5$ \\
\hline $\begin{array}{l}\text { Average daily exercise } \\
\text { time [min] }\end{array}$ & $5.8 \pm 2.7$ & $6.2 \pm 3.1$ \\
\hline \multicolumn{3}{|c|}{$\begin{array}{l}B M I \text { - body mass index, } S B P \text { - systolic blood pressure, } \\
D B P \text { - diastolic blood pressure, } H R \text { - heart rate (beats per minute), } \\
T G \text { - triglyceride, } T C \text { - total cholesterol, } L D L-C \text { - low-density } \\
\text { lipoprotein cholesterol, } H D L-C \text { - high-density lipoprotein cholesterol, } \\
\text { ApoA1 - apoprotein } A 1, \text { apoB100 - apoprotein B100, Lp (a) } \\
\text { lipoprotein (a), FBG - fasting blood glucose, Cr - creatinine, BUN } \\
\text { - blood urea nitrogen, Hs-CRP-high-sensitivity C-reactive protein. }\end{array}$} \\
\hline
\end{tabular}


Table II. Comparisons of characteristics 3 months later

\begin{tabular}{|c|c|c|}
\hline Variables & $\begin{array}{l}\text { Exercise } \\
(n=42)\end{array}$ & $\begin{array}{l}\text { Control } \\
(n=50)\end{array}$ \\
\hline Age [years] & $50.4 \pm 5.8$ & $48.5 \pm 5.3$ \\
\hline Male, $n(\%)$ & $31(73.8)$ & $35(70.0)$ \\
\hline $\mathrm{BMI}\left[\mathrm{kg} / \mathrm{m}^{2}\right]$ & $21.6 \pm 2.4$ & $23.5 \pm 2.7$ \\
\hline Smoking, $n(\%)$ & $11(26.2)$ & $135(26.0)$ \\
\hline $\mathrm{SBP}[\mathrm{mm} \mathrm{Hg}]$ & $113.8 \pm 10.3$ & $118.4 \pm 10.7$ \\
\hline $\mathrm{DBP}[\mathrm{mm} \mathrm{Hg}]$ & $71.7 \pm 7.9$ & $72.0 \pm 8.8$ \\
\hline $\mathrm{HR}[\mathrm{bpm}]$ & $72.6 \pm 5.4$ & $76.2 \pm 6.2$ \\
\hline TG $[\mathrm{mmol} / \mathrm{l}]$ & $1.4 \pm 0.3$ & $1.6 \pm 0.3$ \\
\hline $\mathrm{TC}[\mathrm{mmol} / \mathrm{l}]$ & $5.3 \pm 0.5$ & $5.7 \pm 0.5$ \\
\hline LDL-C [mmol/l] & $3.1 \pm 0.4^{*}$ & $3.8 \pm 0.4$ \\
\hline $\mathrm{HDL}-\mathrm{C}[\mathrm{mmol} / \mathrm{I}]$ & $1.2 \pm 0.3^{*}$ & $0.9 \pm 0.2$ \\
\hline apoA1 [mmol/l] & $1.1 \pm 0.2$ & $0.9 \pm 0.2$ \\
\hline apoB100 [mmol/l] & $1.5 \pm 0.3$ & $2.0 \pm 0.4$ \\
\hline $\mathrm{Lp}(\mathrm{a})[\mathrm{mg} / \mathrm{l}]$ & $104.6 \pm 10.7^{\star}$ & $136.8 \pm 18.9$ \\
\hline $\mathrm{FBG}[\mathrm{mmol} / \mathrm{l}]$ & $5.3 \pm 0.4$ & $5.6 \pm 0.5$ \\
\hline $\mathrm{Cr}[\mu \mathrm{mol} / \mathrm{ll}]$ & $94.1 \pm 10.7$ & $93.3 \pm 9.0$ \\
\hline $\mathrm{BUN}[\mathrm{mmol} / \mathrm{l}]$ & $5.4 \pm 1.1$ & $5.5 \pm 1.0$ \\
\hline $\mathrm{Hs}-\mathrm{CRP}[\mathrm{mg} / \mathrm{l}]$ & $3.1 \pm 1.2^{*}$ & $4.4 \pm 1.2$ \\
\hline $\begin{array}{l}\text { ROCK } 2 \text { concentration } \\
{[\mathrm{mg} / \mathrm{ml}]}\end{array}$ & $27.6 \pm 4.3^{*}$ & $34.6 \pm 5.2$ \\
\hline $\begin{array}{l}\text { NO concentration } \\
{[\mu \mathrm{mol} / \mathrm{l}]}\end{array}$ & $12.2 \pm 2.0$ & $10.7 \pm 1.7$ \\
\hline $\begin{array}{l}\text { Average daily exercise } \\
\text { time [min] }\end{array}$ & $37.4 \pm 4.3^{*}$ & $16.5 \pm 7.5$ \\
\hline
\end{tabular}

cyte ROCK2 concentration, multivariate linear regression analysis was performed. After adjusting for age and gender (model 1), body mass index (BMI), smoking, LDL-C, Lp(a), hs-CRP, NO and exercise time were significantly associated with leukocyte ROCK2 concentration. After further adjusting for BMI, smoking, LDL-C and Lp(a) (model 2), only $\mathrm{NO}$ and exercise time remained significantly associated with leukocyte ROCK2 concentration, with an odds ratio of 0.825 (exercise group versus control group, 95\% confidence interval $(\mathrm{Cl})$ : $0.783-0.866, p<0.05)$ for NO and an odds ratio of 0.813 (exercise group versus control group, $95 \% \mathrm{Cl}: 0.748-0.872, p<0.05)$ for exercise time.

\section{Discussion}

Our preliminary research revealed that in subjects with dyslipidemia without previous lipid-lowering therapy, 3 months of moderate aerobic exer- cise is beneficial for dyslipidemia improvement. Furthermore, moderate aerobic exercise could attenuate leukocyte ROCK2 concentration and promote serum NO concentration. In addition, with respect to the clinical relevance, we consider that there is high cost-effectiveness of recommending moderate aerobic exercise in both dyslipidemic subjects and healthy populations for its potential benefits in reducing the incidence of cardiovascular diseases.

Notably, dyslipidemia is one of the major modifiable risk factors for atherosclerosis and ASCVD [17]. Through eliciting oxidative stress and inflammation, an increased serum cholesterol level impairs endothelial function and promotes leukocyte ROCK2 concentration, and that is the underlying mechanism by which statins confer their pleiotropic effects on the cardiovascular system [18]. In short, moderate aerobic exercise is beneficial for lipid lowering and endothelium protection [19]. However, whether the benefits derived from this kind of lifestyle modification is attributed to reduced leukocyte ROCK 2 concentration has not been fully investigated yet. ROCK2 is known to be highly expressed in the cardiac muscle and vascular system. After being activated by Rho-GTPase, ROCK2 phosphorylates $\mathrm{Ser}^{19}$ of myosin light chain and subsequently increases cellular contractility, impairs endothelial function, and enhances vascular smooth muscle cell migration and leukocyte infiltration [20]. Indeed, numerous previous studies have consistently revealed that increased leukocyte ROCK2 concentration is associated with atherosclerotic development. For example, Yoneda et al. found that rather than ROCK1-depleted cells, phagocytic uptake of fibronectin-coated beads is down-regulated in ROCK2-depleted cells [21]. In addition, Qian Zhou et al. reported that through inhibiting peroxisome proliferator-activated receptor- $\gamma$-mediated reversal of cholesterol transport in macrophages, ROCK2 contributed to atherosclerosis development and progression [22]. Moreover, Okamoto et al. revealed that compared with wild type mice, cardiac-specific deletion of ROCK2 prevented cardiac hypertrophy as stimulated by angiotensin-II [23]. Despite compelling evidence indicating the close relationship between ROCK2 and cardiovascular diseases, no selective inhibitor for ROCK2 is currently approved for clinical application.

Interestingly and importantly, our present research revealed that short-term moderate aerobic exercise not only could modulate cholesterol metabolism but also could improve endothelial function and reduce leukocyte ROCK2 concentration. Indeed, many studies have indicated that moderate aerobic exercise is beneficial for cholesterol lowering and glucose regulation. In addition, moderate aerobic exercise augments tissue perfusion 
and reduces oxidative stress, which may lead to improvement of endothelial function. Nonetheless, whether these benefits of moderate aerobic exercise are associated with ROCK2 alteration is not fully clear yet. The results from our present research supported the notion that moderate aerobic exercise is beneficial for reduced leukocyte ROCK2 concentration. As shown in Table II, the leukocyte ROCK2 concentrations were decreased in both groups after 3 months as compared with baseline, and it might be at least partially due to increased exercise time, and the fact that the magnitude of the decrease of leukocyte ROCK2 concentration was greater in the exercise group further supported this notion. Furthermore, multivariable linear regression analysis revealed that, after extensively adjusting for potential covariates, exercise time remained significantly associated with leukocyte ROCK2 concentration. With respect to the physiological effects of moderate aerobic exercise on the cardiovascular system, we considered that the following mechanisms might explain our findings. First, as mentioned above, moderate aerobic exercise is beneficial to augment tissue perfusion and thereby reduce oxidative stress [13]. Since oxidative stress could up-regulate leukocyte ROCK2 concentration, it was possible that through ameliorating oxidative stress, moderate aerobic exercise decreased leukocyte ROCK2 concentration. Second, since an increased cholesterol level is always accompanied by increased generation of isoprenoid intermediates, critical substrates for leukocyte ROCK2 concentration increased [24]. Therefore, cholesterol lowering induced by moderate aerobic exercise may have led to reduced leukocyte ROCK 2 concentration. In addition, it has been reported that $L p(a)$ is also an important lipoprotein associated with inflammation and oxidation. Therefore, reduced $\mathrm{Lp}(\mathrm{a})$ level in the exercise group might also have contributed to the favorable change of NO production and ROCK2 expression. Last but not the least, increased NO concentration by moderate aerobic exercise could antagonize oxidative stress in one aspect, and in the other aspect, increased serum NO concentration reduced leukocyte infiltration and thereby mitigated inflammation, suppressed ROCK 2 expression and protected DNA of endothelium from damage [25-27].

There are several limitations of our study. First, although the data supported that moderate aerobic exercise was beneficial for lipid modification, endothelium protection and leukocyte ROCK2 concentration diminishment, the study is limited by its small scale and a short-term follow-up. Therefore, the data could not be used for inferring causality, but may be used for hypothesis generation, which is warranted for confirmation by future research. Second, since this was not a randomized study, so there was potential residual confounding which could not be adjusted. Third, the results from this study could not be generalized to other ethnic populations.

In conclusion, this study showed that in populations with newly diagnosed dyslipidemia, moderate aerobic exercise could favorably regulate cholesterol metabolism. Moreover, this kind of lifestyle modification is beneficial for improving endothelial function, which may be due to its effect on attenuating leukocyte ROCK2 concentration.

\section{Acknowledgments}

Huadong Bai and Jingchun Sun are co-first authors.

We greatly appreciate the help Dr. Wu Cong provided to improve the writing of our paper.

\section{Conflict of interest}

The authors declare no conflict of interest.

\section{References}

1. Weissberg PL, Bennett MR. Atherosclerosis: an inflammatory disease. N Engl J Med 1999; 340: 1928-9.

2. Forstermann U, Munzel T. Endothelial nitric oxide synthase in vascular disease: from marvel to menace. Circulation 2006; 113: 1708-14.

3. Bonetti PO, Lerman LO, Lerman A. Endothelial dysfunction: a marker of atherosclerotic risk. Arterioscler Thromb Vasc Biol 2003; 23: 168-75.

4. Hung MJ, Cherng WJ, Hung MY, et al. Increased leukocyte Rho-associated coiled-coil containing protein kinase activity predicts the presence and severity of coronary vasospastic angina. Atherosclerosis 2012; 221: 521-6.

5. Wang HW, Liu PY, Oyama N, et al. Deficiency of ROCK1 in bone marrow-derived cells protects against atherosclerosis in LDLR-/- mice. FASEB J 2008; 22: 3561-70.

6. Liu PY, Chen JH, Lin LJ, Liao JK. Increased Rho kinase activity in a Taiwanese population with metabolic syndrome. J Am Coll Cardiol 2007; 49: 1619-24.

7. Noma K, Oyama N, Liao JK. Physiological role of ROCKs in the cardiovascular system. Am J Physiol Cell Physiol 2006; 290: C661-8.

8. Loirand G, Sauzeau V, Pacaud P. Small G proteins in the cardiovascular system: physiological and pathological aspects. Physiol Rev 2013; 93: 1659-720.

9. Cai A, Li L, Zhou Y. Pathophysiological effects of RhoA and Rho-associated kinase on cardiovascular system. J Hypertens 2016; 34: 3-10.

10. Hattori T, Shimokawa H, Higashi M, et al. Long-term inhibition of Rho-kinase suppresses left ventricular remodeling after myocardial infarction in mice. Circulation 2004; 109: 2234-9.

11. Nohria A, Grunert ME, Rikitake Y, et al. Rho kinase inhibition improves endothelial function in human subjects with coronary artery disease. Circ Res 2006; 99: 1426-32.

12. Wolfrum S, Dendorfer A, Rikitake $Y$, et al. Inhibition of Rho-kinase leads to rapid activation of phosphatidylinositol 3-kinase/protein kinase Akt and cardiovascular protection. Arterioscler Thromb Vasc Biol 2004; 24: 1842-7.

13. Sandor B, Nagy A, Toth A, et al. Effects of moderate aerobic exercise training on hemorheological and laborato- 
ry parameters in ischemic heart disease patients. PLoS One 2014; 9: e110751.

14. Mazurek K, Krawczyk K, Zmijewski P, Norkowski H, Czajkowska A. Effects of aerobic interval training versus continuous moderate exercise programme on aerobic and anaerobic capacity, somatic features and blood lipid profile in collegate females. Ann Agric Environ Med 2014; $21: 844-9$.

15. Drenowatz C, Sui X, Fritz S, et al. The association between resistance exercise and cardiovascular disease risk in women. J Sci Med Sport 2015; 18: 632-6.

16. Meldrum DR, Gambone JC, Morris MA, Esposito K, Giugliano D, Ignarro LJ. Lifestyle and metabolic approaches to maximizing erectile and vascular health. Int J Impot Res 2012; 24: 61-8.

17. Boekholdt SM, Hovingh GK, Mora S, et al. Very low levels of atherogenic lipoproteins and the risk for cardiovascular events: a meta-analysis of statin trials. J Am Coll Cardiol 2014; 64: 485-94.

18. Cai A, Zhou Y, Li L. Rho-GTPase and atherosclerosis: pleiotropic effects of statins. J Am Heart Assoc 2015; 4: e002113.

19. Zheng C, Azcutia V, Aikawa E, et al. Statins suppress apolipoprotein CIII-induced vascular endothelial cell activation and monocyte adhesion. Eur Heart J 2013; 34: 615-24.

20. Etienne-Manneville S, Hall A. Rho GTPases in cell biology. Nature 2002; 420: 629-35.

21. Yoneda A, Multhaupt HA, Couchman JR. The Rho kinases I and II regulate different aspects of myosin II activity. J Cell Biol 2005; 170: 443-53.

22. Zhou Q, Mei Y, Shoji T, et al. Rho-associated coiledcoil-containing kinase 2 deficiency in bone marrowderived cells leads to increased cholesterol efflux and decreased atherosclerosis. Circulation 2012; 126: 2236-47.

23. Okamoto R, Li Y, Noma K, et al. FHL2 prevents cardiac hypertrophy in mice with cardiac-specific deletion of ROCK2. FASEB J 2013; 27: 1439-49.

24. Loprinzi PD, Crespo CJ, Andersen RE, Smit E. Association of body mass index with cardiovascular disease biomarkers. Am J Prev Med 2015; 48: 338-44.

25. Nguyen DCA, Montezano AC, Burger D, Touyz RM. Angiotensin II, NADPH oxidase, and redox signaling in the vasculature. Antioxid Redox Signal 2013; 19: 1110-20.

26. Pokrywka A, Zembron-Lacny A, Baldy-Chudzik K, Orysiak J, Sitkowski D, Banach M. The influence of hypoxic physical activity on cfDNA as a new marker of vascular inflammation. Arch Med Sci 2015; 11: 1156-63.

27. Danese E, Lippi G, Sanchis-Gomar F, et al. Physical exercise and DNA injury: good or evil? Adv Clin Chem 2016 in press. 